
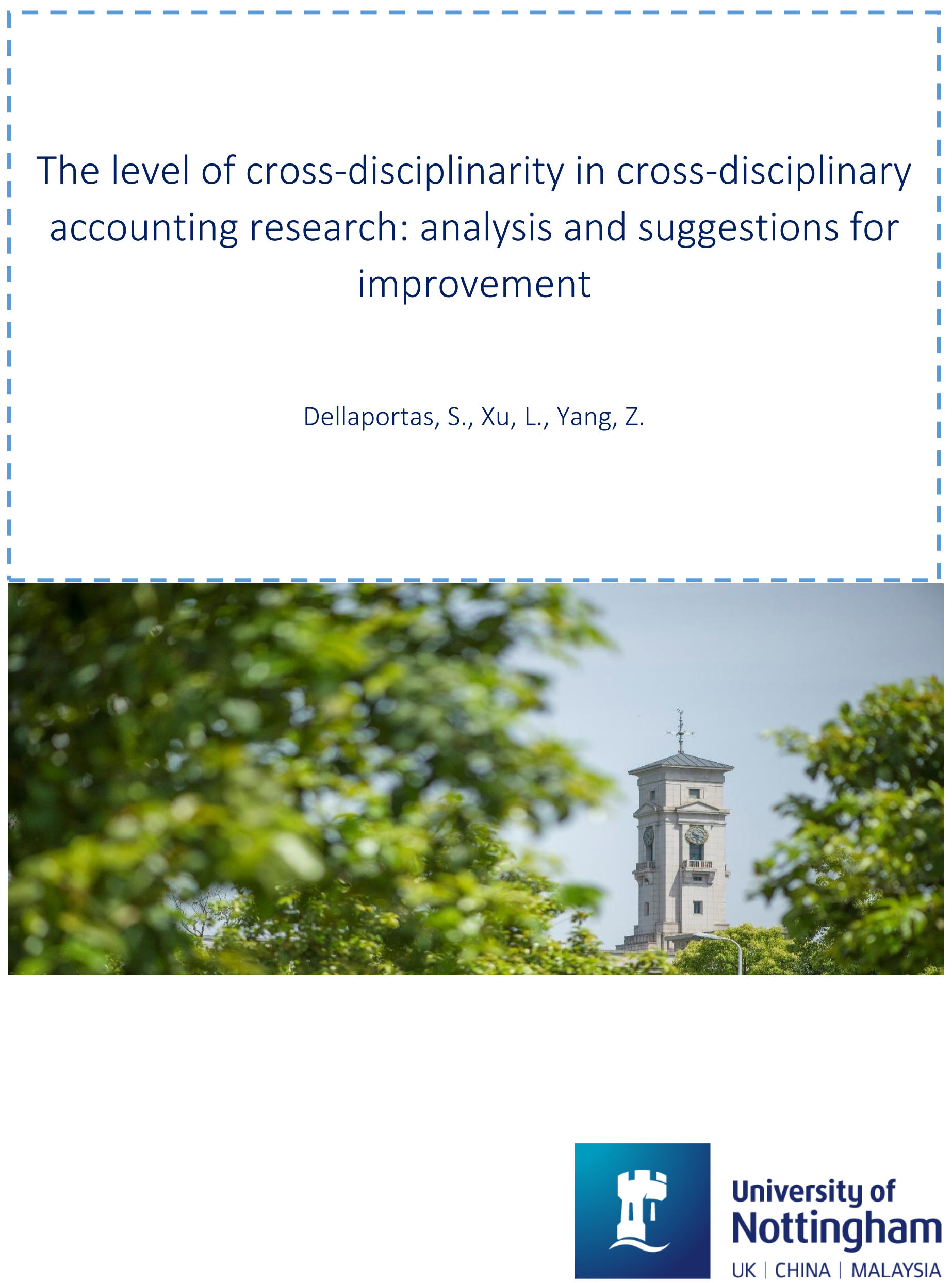
University of Nottingham Ningbo China, 199 Taikang East Road, Ningbo, 315100, Zhejiang, China.

First published 2020

This work is made available under the terms of the Creative Commons Attribution 4.0 International License:

http://creativecommons.org/licenses/by/4.0

The work is licenced to the University of Nottingham Ningbo China under the Global University Publication Licence:

https://www.nottingham.edu.cn/en/library/documents/researchsupport/global-university-publications-licence-2.0.pdf 


\title{
The Level of Cross-disciplinarity in Cross-disciplinary Accounting Research: Analysis and Suggestions for Improvement
}

\author{
Steven Dellaportas \\ (corresponding author) \\ Department of Finance, Accounting \& Economics \\ Nottingham University Business School, Ningbo, China \\ 199 Taikang East Road Ningbo, 315100, China \\ steven.dellaportas1@gmail.com \\ Lina $\mathrm{Xu}$ \\ School of Accounting \\ RMIT University \\ 445 Swanston St \\ Melbourne, VIC 3000, Australia \\ lina.xu@rmit.edu.au \\ Zhiqiang Yang \\ School of Accounting \\ Guangdong University of Finance and Economics' \\ 21 Luntou Rd, Haizhu Qu, \\ Guangzhou, Guangdong, China \\ tyangzq@gdufe.edu.cn
}

Funding: This research did not receive any specific grant from funding agencies in the public, commercial, or not-for-profit sectors.

Key words: cross-disciplinary research, integration, interaction, collaboration, cognition 


\section{Introduction}

The benefits of cross-disciplinary research are widely acknowledged in a variety of disciplines, linking it with innovation, creative problem-solving, new meanings and the ability to advance knowledge with intellectual breakthroughs (Aboelela et al., 2007; Carayol \& Thi, 2005; Choi \& Pak, 2006; Morillo et al., 2003; Rafols et al., 2012). The benefits of crossdisciplinary research come from being attentive to ideas and processes developed in diverse fields in an endeavour to find new meaning using fresh perspectives (Alvesson \& Gabriel, 2013). Hopwood (1983) brought cross-disciplinarity to the fore in accounting by acknowledging the importance of understanding accounting in its social and organisational context. Since its inception in the 1970s, cross-disciplinary research in accounting has seen a significant stream of scholarship established to develop an epistemic community with regular conferences, a core group of scholars, and academic journals dedicated to its dissemination (Jeacle \& Carter, 2014; Parker, 2005). Definitions of cross-disciplinary research in the accounting literature, often referred to as 'inter-disciplinary research', differ in language, but the elements all point in a similar direction. They refer to the integration of multiple theories, or the application of theory(ies) from outside of the discipline in which the research is located (e.g. O’Dwyer \& Unerman, 2014; Guthrie \& Parker, 2014). However, such definitions narrowly focus on conceptual integration without due recognition of other elements. More than conceptual integration, the meaning of 'cross-disciplinary' research in the present study adopts a wider ambit to include research using multiple theories and research methods, conducted by teams of scholars from diverse disciplines to develop new conceptual insights (Carr et al., 2018; Rosenfield, 1992; Morillo et al., 2003; Stock \& Burton, 2011). ${ }^{1}$

The aim of this study is to understand and examine the nature of cross-disciplinary accounting research through three inter-related objectives. First, this study constructs a multi-dimensional definitional framework to develop a comprehensive understanding of cross-disciplinary research. The framework is built on the premise that cross-disciplinary research is more than bringing together theories or concepts from distinct disciplines but is constructed on two key dimensions: the 'integration' dimension (theories and methods); and the 'interaction' dimension (people and disciplines) in which scholars from unrelated disciplines work together to create epistemological shifts. The dimensions derived from the framework not only influence how cross-disciplinarity is conceptualised but also provide the mechanism to evaluate cross-disciplinary research in a systematic manner. The second

\footnotetext{
${ }^{1}$ The term 'inter-disciplinarity' is commonly used in the accounting literature as an umbrella term to cover all types of cross-disciplinary research. The present study relies on the term 'cross-disciplinary', characterizing all typologies of inter-disciplinarity, to distinguish from the more generic use of the term 'inter-disciplinary research'.
} 
objective of this study is to evaluate cross-disciplinarity in accounting with an empirical analysis of published research to help position existing scholarship within the definitional framework. The study assesses how existing cross-disciplinary research complements or diverges from the dimensions of the framework. The third objective extends the empirical analysis by examining the implications of cross-disciplinary research using citation data to examine not only the impact of cross-disciplinary research but to also examine how the dimensions of cross-disciplinarity influence the frequency of citations. The latter two objectives work together to help specify the elements necessary to forge cross-disciplinary research in accounting.

The development of the dimensions underpinning the definitional framework is guided by normative propositions and empirical evidence drawn from diverse literatures to explain the meaning of cross-disciplinarity. Research literature was analysed thematically to identify and describe the key components of cross-disciplinarity which were then used to construct the framework. Data relating to the second objective were collected from the details and content of articles (informing theories, methods of data analyses, author names and affiliations) published in three leading cross-disciplinary accounting research journals: Accounting, Auditing \& Accountability Journal (AAAJ); Accounting, Organizations and Society (AOS); and Critical Perspectives on Accounting (CPA). The variables of published articles pertinent to the two underlying dimensions (integration and interaction) were analysed using factor analysis to test the extent to which the dimensions are related to the level of crossdisciplinary accounting research. The findings show that published articles in crossdisciplinary accounting research were well represented by the integration dimension involving conceptual synthesis, but published articles were less frequently represented within the interaction dimension in which scholars collaborate across disciplines. The third objective relies on citation data collected from Google Scholar to assess the relationship between the dimensions and level of citations. The findings show that both the integration dimension and interaction dimension contributed to the level of citations.

The paper is structured in four major sections. The relevant literature on the meaning of cross-disciplinary research is surveyed in Section 2 to identify and construct the components necessary to develop the definitional framework. The methodology underlying the empirical testing of the definitional framework is explained in Section 3. The findings in Section 4 document the extent and focus of cross-disciplinarity in accounting as well as the impact of cross-disciplinary research measured in terms of citations. A discussion of the findings is provided in Section 5, and finally conclusions are presented in Section 6.

\section{Literature review}


Proponents of cross-disciplinary accounting research point to its benefits, referring to its ability to open up or explore new directions of accounting thought. For example, Dumay and Guthrie (2019) define cross-disciplinary accounting research in terms of its propensity to explore and critically debate accounting in its socio-economic and political context; or as Jeacle and Carter (2014) suggest, cross-disciplinary research opens up new spaces of inquiry through innovation and creativity. Fogarty (2014, p.1266) similarly states: "Interdisciplinary accounting research invites us to look at phenomena .... in different ways". Gendron and Rodrigue (in press) highlight the multiplicity evident in innovative research, claiming that knowledge production occurs in a variety of ways, including different theoretical and methodological perspectives, adopting a more global or local focus, and engagement with accountants in practice. Canning et al. $(2018$, p.166) claim that the literature in a given research domain will be richer when the object of study is approached from different angles and paradigms: "Our understanding of auditing is likely to be more comprehensive when functionalist, interpretive, and critical research projects are simultaneously undertaken and achieved". In the critical accounting literature, scholars promoting boundary-spanning research rely on the essence of cross-disciplinarity, even when it is not explicitly stated, by calling for theoretical and epistemological diversity (Gendron, 2018a; Richardson, 2015). When definitions of cross-disciplinarity, ground accounting research in a range of disciplines, the spectrum of world views enriches knowledge keeping it from becoming stagnant.

Definitions of cross-disciplinary research in accounting when they appear in the literature are mostly normative or anecdotal and visibly absent of empirical, longitudinal or large-scale studies. Rarely does research in accounting critically evaluate the meaning of cross-disciplinary research beyond its rudimentary definition. Whilst comprehensive analysis on the meaning of cross-disciplinarity is rare, claims of cross-disciplinary research in accounting are abundant. For example, cross-disciplinary research has been linked to knowledge creation and the diversity in concepts in accounting research including intellectual capital (Dumay \& Guthrie, 2019), economic inequality (Tweedie \& Hazelton, 2019), and public sector accounting or accountability (Goddard, 2010; Jacobs, 2012). Further, there is a preponderance of cross-disciplinary research in accounting that has for several decades addressed accountability issues in social and environmental accounting (Tweedie \& Hazelton, 2019).

The term cross-disciplinary is best understood when it is contrasted with monodisciplinary in which the research is conducted within the framework of an epistemologically and methodologically homogeneous field (O'Dwyer \& Unerman, 2014). Mono-disciplinary research is represented in the array of accounting research predominantly relying on agency theory and the efficient markets hypothesis to understand the impact of changes in financial accounting on stock valuation. Critical scholars question the contribution of mainstream financial accounting research when it is limited to a narrow range of topics and research methods analysed within conventional economic theory (Moser, 2012; Reiter \& Williams, 2002). Research that is narrowly constructed and applied ignores what is going on outside the 
researcher's specialized field, losing its potential to advance knowledge (Alvesson \& Sandberg, 2013). Despite the limitations of mono-disciplinary research, there is potential for new insights to evolve and develop incrementally with every publication adding some new finding or idea. However, cross-disciplinary research, more than mono-disciplinary research, has the capacity to create new knowledge by combining the perspectives of multiple disciplines (Aboelela et al., 2007).

The elusiveness of the phrase 'cross-disciplinary research' arises in part because it is not a unitary concept but is comprised of multiple 'disciplinarities', ranging from simple theoretical and methodological borrowing, such as that which is common in accounting, to theoretical enrichment or the development of new world views, more commonly cited in the physical sciences. The term inter-disciplinary is often used as an umbrella term to address a typology of cross-disciplinary research comprised of three disciplinarities: multi-disciplinary, inter-disciplinary and trans-disciplinary (see Choi \& Pak, 2006; Huutoniemi et al., 2010; Morillo et al., 2003; Porter et al., 2006). The three disciplinarities are not mutually exclusive but sit at different points on a continuum distinguished by the level of theoretical, methodological and disciplinary integration. At one end of the continuum is multi-disciplinary research, where scholars rely on multiple perspectives to examine a phenomenon. This can be performed by a single researcher or in teams, but regardless of the extent of collaboration, there is no real attempt to bridge disciplinary boundaries or generate new integrative knowledge (Stock \& Burton, 2011). Whilst multi-disciplinary research draws on knowledge from diverse disciplines bringing different perspectives to the issue of investigation, the research remains within disciplinary boundaries, limiting its ability to extend understanding beyond the discipline in which the research is located. This approach to research is not conceptually path-breaking but sheds light on aspects of a problem from different perspectives, leading to immediate but possibly short-lived solutions (Rosenfield, 1992).

At mid-point of the continuum is inter-disciplinary research, representing a more advanced stage of cross-disciplinarity, regarded as a step up from multi-disciplinary research by attempting to link and harmonise theoretical, conceptual and methodological identities. The process of inter-disciplinary research seeks input from a variety of unrelated disciplines to create new knowledge, but rarely does it lead to a new hybrid field of research. The major difference from multi-disciplinarity lies in the scholarly integration where inter-disciplinary research attempts to bridge disciplinary viewpoints, which is not as evident in multidisciplinary research. At the other end of the continuum is trans-disciplinary research, in which the traditional boundaries of disciplinary research are transcended to converge disparate disciplines to form a new hybrid discipline. The researcher in trans-disciplinary research will reach across sectors and disciplines to work with counterparts to strengthen the basis of their research. It is in trans-disciplinary research where researchers bring themselves to the fringes of their disciplinary fields to form new concepts and ideas. Trans-disciplinary research represents the highest form of integration, involving the application of crossdisciplinary concepts as well as scholars from multiple disciplines to combine knowledge and 
skill from diverse disciplinary domains (Stock \& Burton, 2011). Trans-disciplinarity synthesises new disciplines and theory to form a hybrid concept shared equally among the disciplines (Stock \& Burton, 2011).

\subsection{A definitional framework of cross-disciplinary research}

Despite the ongoing quest for cross-disciplinarity, its meaning as it appears in the literature is imprecise, and when defined, it is not always shared similarly by researchers within or between disciplinary domains (e.g. Huutoniemi et al., 2010; Klein, 2008; Steele \& Stier, 2000; Whitfield \& Reid, 2004). The following discussion probes conceptions of crossdisciplinarity published in many literatures to identify and articulate the key components described therein. The framework depicted in Figure 1 is developed by explaining and linking key variables identified in academic research, defining and explaining cross-disciplinary research. ${ }^{2}$ The framework brings together two dimensions identified as key elements of cross-disciplinary research: integration (bodies of knowledge and research approaches) and interaction (collaboration combining expertise and skill). These dimensions represent the most detailed discussion on cross-disciplinarity and are at the core of understanding such research (see Figure 1 for definitions of key terms). Notions of integration and interaction appear interchangeably in the literature; however, rather than treat them equally or jointly, the following discussion examines the elements separately. Understanding these dimensions is important to this research as it will help to distinguish the typologies of cross-disciplinarity (multi/-inter/-trans-disciplinary research) and show how they may account for the development of new ways of thinking.

\section{Insert Figure 1 about here}

\subsection{The integration dimension}

What visibly emerged from the literature is the importance of integration in crossdisciplinarity, consequently selected as the first dimension of the definitional framework. Integration is referred to by authors in cross-disciplinarity as reflecting and merging diverse knowledge sources. For example, researchers describe integration as the number of bodies of knowledge involved in the research and the extent to which these knowledge sources are related or disparate (Rafols \& Meyer, 2010; Porter et al., 2006). In broad terms, knowledge in cross-disciplinarity refers to theories, concepts, disciplinary viewpoints, or epistemological beliefs. Conceptual integration attempts to overcome the limitations of individual disciplinary

\footnotetext{
2 The framework and its elements rely on a selection of articles from diverse disciplines, downloaded, studied and $^{\text {annotated }}$ based on the article's discussion of cross_disciplinarity that moved dialogue or analysis beyond a basic definition. The articles were studied to identify key themes underpinning the definition of cross-disciplinary research, to construct a framework of crossdisciplinarity. Relevant articles in the accounting literature on understanding cross-disciplinarity were relied upon to elucidate relevant issues and give context to cross-disciplinary research in accounting.
} 
domains by drawing on diverse ideas, accepting that the differences and sometimes tensions which manifest between domains are reflected insightfully in the development of new thoughts and ideas.

Whilst cross-disciplinarity is almost always discussed in terms of knowledge, methodological integration using diverse methods of data collection is equally important in the definition of cross-disciplinarity, albeit discussed less frequently in the literature. Like knowledge, methodological cross-disciplinarity occurs when data or research methods are combined to suit the context and not simply juxtaposed or borrowed from one field to another (Huutoniemi et al., 2010). Methodological integration can be categorised by the different ways methods may be integrated. Multimethods research uses more than one method from within the quantitative or qualitative research paradigm (Creswell, 2015). However, the highest level of methodological integration occurs not from multimethods but from mixed methods, characterised by the purposeful mixing of both qualitative and quantitative methods of data collection and analysis (Creswell, 2015). The different approaches to research provided by mixed methods has the potential to contribute to an enhanced understanding of the research that is unlikely to be provided by one method alone. Co-mingling methodological approaches becomes critical to cross-disciplinarity when it becomes the primary mechanism to facilitate integrative analysis. Consistent with the notion of cross-disciplinarity, the mixed methods approach to research may be potentially disruptive (but perhaps inspiring) to accounting research when it introduces quantitative methods to a community that has historically relied on qualitative methods of research (Richardson, 2015). However, Loo and Lowe (2011) warn that the benefits of the mixed methods approach may be overstated when it is applied without due consideration of the rationale that best supports the research question, suggesting that the deficiencies in singular research methods may also be present in mixed methods.

Scholars distinguish levels of cross-disciplinarity based on notions of weak and strong, or small and large, forms of integration (Rossini \& Porter, 1979; Rosenfield, 1992; Stock \& Burton, 2011). Multi-disciplinary research is the most common approach to integrative research, and is represented by low levels of integration in which the theoretical components involved in the research stand on their own. In multi-disciplinary research, the subject under study is approached from different angles, possibly using different research approaches, but integration is not necessarily accomplished. Research can be multi-disciplinary without being cross-disciplinary when diverse disciplines are adopted in a single project but not integrated (Schummer, 2004). Multi-disciplinary research suggests that disciplinary boundaries are crossed rather than integrated and thus would appear to emphasise low levels of integrated research (Stock \& Buton, 2011). Trans-disciplinary research represents the highest level of integration when it involves a shared, over-arching theoretical framework combining knowledge and methods from different disciplines into a single cohesive understanding. Inter-disciplinary research sits between being multi-disciplinary at one end, where a problem is viewed from multiple perspectives, and trans-disciplinary at the other end, where theories 
converge to develop a new way of thinking or a new (inter)discipline (Porter et al., 2006). Inter-disciplinary research has the ability to create its own conceptual and methodological identity, carrying with it a more coherent way of thinking, but is not always justified on the basis of a cognitive shift. While inter-disciplinary research between two disciplines may be strong, this does not necessarily mean a high degree of trans-disciplinarity.

\subsection{The interaction dimension}

Another critical component of a vast majority of definitions on cross-disciplinary research refers not only to the integration of concepts but also to the interaction of researchers from diverse fields working collaboratively in teams. Researcher interaction is typically assessed in terms of the amount of contact and the degree of information sharing between members of the research team (Aboelela et al., 2007; Schummer, 2004). A distinctive feature of researcher collaboration is the bringing together of research expertise and knowledge originating from different disciplines to challenge the thinking of each team member and enhance understanding (van Rijnsoever \& Hessels, 2011; Carayol \& Thi, 2005). The notions of integration and interaction are not mutually exclusive, as the integration of disciplines involves various forms of interaction between research environments, including individual researchers, organisations and the resources available to them to tackle research problems. Cross-disciplinary collaboration does not necessarily mean that organisational boundaries must be crossed: cross-disciplinary collaborations can occur between researchers working across departments in the same university. However, it does mean that researchers in different disciplines meet at the interface to help form new insights.

Morillo et al. (2003) suggest that interaction is distinguished among the typologies of disciplinarities based on different levels of collaboration (weak/strong, small/large) which range from the simple communication of ideas to the mutual interaction of skills and knowledge. Different points along the continuum of cross-disciplinarity represent qualitatively different forms of collaboration. Multi-disciplinary research is characterised as having low degrees of interaction which necessitate very little, if any, collaboration between researchers. Rosenfield (1992) explains multi-disciplinary interaction as teams comprised of diverse disciplinary expertise but with each discipline working independently, with the results usually brought together at the end. In the conduct of inter-disciplinary research, scholars from different disciplines come together to develop new insights, but the results are reported in a partial, discipline-by-discipline sequence. The knowledge developed from interdisciplinary research is partitioned from other relevant disciplines. Trans-disciplinary research entails the highest amount of collaboration in which teams share not only a common question but also share and borrow methods to achieve a high level of conceptual development constructed from aspects of the researchers' disciplines (Aboelela et al., 2007; Rosenfield, 1992). Scholars in trans-disciplinary research (and to a lesser degree, inter-disciplinary research) explore synergies through an interactive process between participants; whereas in multi-disciplinary research, scholars are sought for their expertise on a particular issue or skill. 
By bringing researchers together from diverse disciplines, information is expected to be exchanged and methodological tools shared to develop ideas more creatively than by working alone.

\subsection{Cognition}

The raison d'être of cross-disciplinarity, as distinct from its process, is its cognitive dynamic to develop new meanings and expand knowledge (Rafols \& Meyer, 2010). More than describing the components of cross-disciplinary research, cognate concepts of crossdisciplinarity focus on the end-point of the integration-interaction nexus as demonstrated by epistemological shifts and new ways of thinking (Wagner et al., 2011; Klein, 2008). Wagner et al. (2011) refer to the process of cognitive change as occurring in the minds of individuals, making it legitimate to talk about cross-disciplinarity as a 'cognitive shift'. However, at the level of the discipline, the focus of cognition is the synthesis of two or more disciplinary perspectives to establish a new level of discourse that transcends existing knowledge boundaries and creates a new sub-discipline. New disciplines in accounting emerge when conventional accounting thought is inadequate to help solve or account for central problems. This is where two or more branches of knowledge merge and develop distinct characteristics and form a new discipline. For example, regulatory control and assurance within the paradigm of auditing for a long time was sufficient to navigate research on organisational control and accountability. However, high profile corporate collapses and an apparent failure of auditors to detect or prevent transgressions gave rise to the broader concept of corporate governance to foster a culture of integrity, positive performance and sustainable business. Following decades of research on corporate governance, it now has its own centre, dominated by functionalist perspectives and quantitative methods of research (Gendron, 2018b).

The relationship and levels of integration and interaction provides the foundation for cognitive shifts (see Figure 2). In multi-disciplinary research, the ingredients of new knowledge are pooled across boundaries, loosely linked by a topical focus without being substantially adapted in the course of integration. The multi-disciplinary activities are carried out in a disciplinary fashion with the ingredients speaking as separate voices (Choi \& Pak, 2006; Huutoniemi et al., 2010). Cognitive shifts are least likely in multi-disciplinary research when researchers from different fields work individually and use the conceptual and methodological tools separately and in an unassimilated way, characterised by low levels of integration and interaction. The interaction in inter-disciplinary research corresponds with the content of disciplinary integration and methodological choice, represented by moderate levels of integration and interaction. Inter-disciplinary research has the capacity to create its own conceptual and methodological identity, carrying with it a more coherent way of thinking, but is not always justified on the basis of a cognitive shift; whereas the ability to change cognitive capacity is attributed to trans-disciplinary research underpinned by high levels of integration and interaction. Trans-disciplinary research enhances the cognitive task to focus on making meaning through a mind-set transformation to generate new 
understandings and encourage collaborative work modes (Choi \& Pak, 2006). The transdisciplinary approach to research opens a full discussion of the problem and leads to more indepth as well as more extensive analyses, potentially leading to shifts in research paradigms and practices. The challenge for participants in trans-disciplinary research is the conflict created by the rigidity of epistemological homogeneity and the potential for conflict and the shortfalls of integration (Huutoniemi et al., 2010).

\section{Insert Figure 2 about here}

The key to understanding the framework is to recognise that not all cross-disciplinary research is integrated across disciplines to the same level. Where research is located on the cross-disciplinarity continuum (multi-/-inter/-trans-disciplinary) is determined by the combined levels of integration and interaction: multi-disciplinary research is best characterised by low levels of integration/interaction; inter-disciplinary research is represented by moderate low levels of integration/interaction; and high levels of integration/interaction are depicted in trans-disciplinary research. In all, integration or interaction is polarised when: at one end, knowledge, methods or collaboration are discrete and conceptually distant, typically reflected in multi-disciplinary research; and the other end, participating research components co-mingle to develop a new theoretical frame becoming more apparent when research moves towards trans-disciplinarity. This is not to say that the same level of cross-disciplinarity cannot be achieved by focusing predominately on one dimension; for example it is possible that cognitive shifts occur from high levels of conceptual integration. Likewise, it is reasonable to suggest that high levels of researcher-toresearcher interaction can also achieve a high level of cross-disciplinarity. However, the two dimensions must be present to some degree for some form of cross-disciplinarity to occur. In all, cross-disciplinary research is a mode of research by individuals or teams with diverse skill and knowledge that integrates perspectives/concepts/theories and/or tools/techniques from two or more bodies of specialised knowledge. ${ }^{3}$ Its purpose is to advance fundamental understanding beyond the scope of a single field of research practice.

\section{Data collection and analysis}

The cross-disciplinary movement in accounting has been supported by the growth of three highly regarded cross-disciplinary accounting research journals, AAAJ, AOS, and CPA

\footnotetext{
${ }^{3}$ The definition of cross-disciplinary research in this study is broadly defined and inclusive of all topics and modes of inquiry. Rather than compartmentalise and exclude positivist modes of research from crossdisciplinarity, the present study embraces an all-inclusive conceptualisation of cross-disciplinary research to include all modes of research. The study embraces economic and financial empiricism as one component of diversity in accounting research and does not exclude the mathematical formulations of positivist accounting. Cross-disciplinarity embraces diversity so that disciplinary perspectives and methods, regardless of their paradigm, converge to develop new ways of thinking.
} 
(Guthrie \& Parker, 2004, de Villiers \& Dumay, 2013). These journals are noted for creating and promoting inter-disciplinary agendas and are central to harnessing and enhancing communities. They serve as virtual meeting places where participants communicate with one another, develop relationships, and secure their sense of belonging to an established community of scholars (Guthrie \& Parker, 2004). These journals were selected because they represent premier accounting research journals with a track record of advancing crossdisciplinary research, capable of making and influencing academic reputations (Ballas \& Theoharakis, 2003; de Villiers \& Dumay, 2013; Endenich \& Trapp, 2016; Gendron \& Baker, 2005; Guthrie \& Parker, 2004, 2014).

Data were collected from the manuscript particulars of articles published in AAAJ, AOS and CPA for the 12-year period 2005-2016. The sample period ends 2016 as representing the most recent year of completed publications at the time data were collected. However, the study period beginning 2005 was selected for three reasons. First, a period of 12 years is considered adequate to deliver a recent and representative depiction of cross-disciplinary research. Second, emerging internet and communication technologies during this period are expected to heighten cross-border and cross-institutional interaction, enhancing the potential for cross-disciplinary research as it pertains to researcher collaboration. Third, data collected from 2005 account for the implications of corporate failures and the enactment of the Sarbanes-Oxley Act, 2002, on accounting research. According to Wood (2016), the average period in which an article is published, from the time of its submission, is less than two years. Data collection commencing 2005 captures research examining alternative explanations on accounting-related issues under scrutiny from corporate transgressions and the global financial crisis. Accordingly, this period also captures the impact of the global financial crisis (GFC) in 2007-2008 on cross-disciplinary research. The sample selection process resulted in a total of 1,937 publications. Adopting an established methodology of selecting only full research articles resulted in the removal of 476 articles, leaving a final sample of 1,461 research articles, distributed across the three journals: AAAJ 479; AOS 453; and 529 CPA. Poems, editorials, response/replies, critiques and commentaries were excluded to ensure a relatively homogenous set of peer-reviewed academic manuscripts (Gordon \& Boland, 2015; Jones \& Roberts, 2005; Oler et al., 2010).

Collecting data on conceptual lenses and the research method relies predominantly on reading the abstract and the relevant sections of the article (theoretical framework and research method) and, when necessary, the entire article. The key words provided by submitting authors provide a valuable reference to confirm the categorisation of data. Data analysis occurred in two stages consistent with the objectives of the study. The first stage entails an analysis of publication characteristics to assess the degree of cross-disciplinary research as benchmarked against the dimensions of the framework. Variables linked to the dimensions of integration and interaction are derived from the characteristics of published articles and analysed using Factor Analysis. Factor analysis is an exploratory technique applied to a set of observed variables to find the underlying factors (subsets of variables) from which 
the observed variables were generated. As the underlying dimensions of cross-disciplinary research cannot be observed directly (Baker, 2014; Kenneth, 2014), factor analysis becomes a useful tool to identify key variables impacting on the measurement and interpretation of the integration and interaction dimensions in cross-disciplinary accounting research. The second stage of data analysis in the present study relies on citation analysis to examine the relationship between the frequency of citations and the dimensions of cross-disciplinarity. ${ }^{4}$ This analysis examines the influence of the cross-disciplinary structure (integration and interaction dimensions) in driving the number of citations. Specifically, to what extent are citations in cross-disciplinary research correlated with the components of the integration dimension (theories and methods) or the interaction dimension (collaboration and disciplines)?

\subsection{Measuring the integration dimension}

The components underlying the integration dimension are quantified based on the number of times that different conceptual lenses and methods of data analysis appear within a single manuscript. The components of the integration dimension are measured as follows.

1. N_conceptual_lens: represents the number of discrete informing conceptual lenses applied to the research in each published article. This variable is calculated by awarding a score of 1 ( 2 or $3 \ldots$ ) when 1 ( 2 or 3 ...) lenses are utilised in the research regardless of the discipline in which the lens is embedded. The score progressively increases, matching the number of lenses adopted within a published manuscript. For example, if an article relies on one discrete lens, a score of 1 is awarded, if an article relies on two discrete lenses, a score of 2 is awarded, and so on. The scoring protocol implicitly assumes that cross-disciplinarity is enhanced with the number of lenses brought to the research. The study design initially focused counting the number of discrete theories but it became evident during initial coding that a number of articles did not rely on a discrete identifiable theory but a framework or propositions constructed from literature(s) relevant to the research. Research reveals that many studies in accounting are descriptive with relatively little theorising (e.g. Broadbent \& Guthrie, 2008; van Helden, 2005; Goddard, 2010). In accounting, scholars also argue that published research relies on different levels of theorisation, ranging from metaphors and differentiation representing early stages of theorisation, to more advanced forms of theorisation (Jacobs, 2012; Llewelyn, 2003). Jacobs (2012) provides specific examples of early stages of theorisation in public sector research, such as accountability, risk, and the value of money, whilst other articles borrow concepts and theories from other

\footnotetext{
${ }^{4}$ Despite citation analysis being widely used, there are some limitations. Counts of citations include all citations regardless of whether the citations are based on praise or criticism. Citation frequency can be influenced by many factors including author's reputation, author's self-citation, the popularity of research area, journal's circulation, and journal's speciality (Reinstein \& Galderon, 2006; Rosenstreich \& Wooliscroft, 2009).
} 
disciplines. Acknowledging the range of theorisation utilised in accounting research, the present study relies on conceptual lens and not a discrete theory to measure the level of conceptual integration.

A conceptual lens is defined in this study as a concept used by researchers to analyse data and facilitate synergistic thinking by linking conceptual and/or factual knowledge or data. Synergistic thinking occurs when concepts are used to analyse data or propositions in the construction of the research. Support for relying on a conceptual lens rather than a discrete theory to measure integration is found in Alvesson and Kärreman (2007), who explain theories as a repertoire of lenses providing insight by illuminating and communicating understandings. In order to gauge the extent of conceptual integration, each conceptual lens in a manuscript is awarded a score of 1 regardless of the stage of theorisation. The conceptual lens representing theorisation of all stages thus becomes the unit of analysis to assess the level of conceptual integration. Where articles use more than one concept to develop a framework, each concept is awarded a score of 1 .

To illustrate the scoring process, reference is made to Lehman et al. (2016), who draws on the conceptual lens of neoliberalism to examine immigration policies in three countries. This study is awarded a score of 2: one score is awarded for the notion of neoliberalism, and a second score is awarded for the notion of 'differentiation' moving accounting research away from its traditional topics. A number of articles in the sample borrow theories from other disciplines to develop a coherent framework of analysis. For example, Davison (2014) developed a theoretical framework to examine visual images in accounting by adopting the work of: Barthes's (1982) rhetoric of the image; Durand's (1987) comprehensive classification; Kress and Van's (2006) meaning of regularities in the way image elements are used; and Varnedoe's repetition (2001). These four theories combine to develop a conceptual framework of visual analysis, resulting in a score of 4. Tucker and Parker's (2013) article is awarded a score of 2 by relying on new institutional theory and contingency theory to understand the management control system in a non-for-profit organisation.

2. N_cross_conceptual_lens: represents the extent of cross-disciplinarity by capturing the number of disciplinary perspectives adopted within a single manuscript. This variable differs from N_conceptual_lens; the latter provides a count of conceptual lenses per manuscript regardless of the discipline. The present variable measures the number of disciplinary perspectives used within a single study. A discipline is considered a branch of knowledge and is captured by identifying the underlying domain from which the conceptual lens is derived. For example, 'capitalism', the 'invisible hand' and 'efficient markets' are derived from the discipline of 'economics', whilst the 'conceptual framework of financial reporting' is derived from the discipline of 'accounting'. The degree of cross-disciplinarity is expected to correlate with the number of disciplinary 
perspectives. For example, an article with two conceptual lenses adopted from the same discipline (e.g. accounting) is considered homogenous and is awarded a score of 1 , whereas an article with two conceptual lenses from unrelated disciplines (e.g. accounting and sociology) is considered heterogenous and is awarded a score of 2 . To illustrate the scoring protocol, Orij (2010) examines the relationship between corporate social disclosures and national culture utilising the conceptual lenses from two distinct disciplines: stakeholder theory derived from organisational management; and Hofstede's national culture framework embedded in cross-cultural communication. This article is awarded a score of 2 for N_cross_conceptual_lens.

3. N_methods: represents the number of methodological approaches applied within a published manuscript. Multiple research approaches imply the potentiality of crossdisciplinarity. Like the number of conceptual lenses, the adoption of diverse methods is another important component of integration (Huutoniemi et al., 2010). A research method is defined as a systematic plan to guide how the research is conducted, explained in terms of strategies or the techniques used to collect data (Smith, 2019). The same scoring procedure as N_conceptual_lens is adopted for N_methods by identifying and tallying the number of research approaches within an article. The coding of research methods draws from a list of commonly applied research methods, developed in prior research by Prather and Rueschhoff (1996), Goddard (2010) and Smith (2019). A review of common approaches adopted from prior research, results in eight broad groupings: experimental, interview, document analysis, survey, critical analysis of literature, theoretical/methodological development, archival and field research. ${ }^{5} \mathrm{~A}$ score of 1 is awarded for published manuscripts relying on one research method, with the score progressively increasing as matching the number of methods used within a published article. ${ }^{6}$ To illustrate the scoring protocol, Tuck (2010) is awarded a score of 2 by relying on two methods (interviews and document analysis) to examine the identity of tax officials in UK tax administration.

\subsection{Measuring the interaction dimension}

The interaction dimension is examined by analysing researcher-to-researcher collaboration inferred in co-authorship. The presence of collaboration is believed to illuminate the extent of interaction between scholars, providing a measure in which researchers bring diverse knowledge and skills to the research (Andrikopoulos \& Kostaris,

\footnotetext{
${ }^{5}$ Field research is used in this study to categorise research relying on the data collection techniques of participation and observation. Methods relying on interviews and case study, classified by some researchers as field research are categorised and coded separately in this study.

${ }^{6}$ Research on profiling in accounting assigns the dominant research method to each article to gauge the most popular research method used in a topic area or a journal (e.g. Goddard, 2010; Chenhall \& Smith, 2011). The present study aims to understand cross-disciplinarity within research articles, making it important to identify all research methods used in an article, because multiple research approaches imply the potentiality of crossdisciplinarity.
} 
2017; Porter et al., 2006; Schummer, 2004). The interaction dimension is measured on two components, the extent of collaboration and the perspectives brought to the project, based on the disciplinary background of the author within collaborative teams.

1. N_authors: represents the presence of researcher-to-researcher interaction. It is increasingly common for researchers to collaborate with colleagues to bring different and complementary skills and ideas to work on a common project (Carayol \& Thi, 2005; Golde \& Gallagher, 1999; Fleischman \& Schuele, 2009). Research evidence suggests that crossdisciplinarity is correlated with the number of co-authors by introducing complementary knowledge and strengths (e.g. Fleischman \& Schuele, 2009; Hart, 2000; Leimu \& Koricheva, 2005). Although one may question whether multiple authorship realises the benefits of collaboration, it is nonetheless considered an indicator of interaction when two or more authors from different disciplinary backgrounds come together to publish research (Qin et al., 1997). Interestingly, collaboration and co-authorship (often with large numbers) are common in the physical sciences where laboratories and expensive equipment are shared, whereas within social science, collaboration in large numbers (four or more) is infrequent (Acedo et al., 2006). In a trend analysis of accounting research journals, Andrikopoulos and Kostaris (2017) note an increasing number of collaborations but that the majority of publications with multiple authors remains low. Disciplines with a higher quantitative content, especially those that require the application of sophisticated econometric models, have a greater propensity for co-authorship (Acedo et al., 2006). As with the integration dimension, a score of 1 ( 2 or 3...) was awarded when there was 1 ( 2 or $3 \ldots$...) contributing authors.

2. N_author_discipline: represents the number of perspectives brought to the project captured by the disciplinary background of the authors. Newell and Galliers (2000) note that cross-disciplinary research relies on joint knowledge from diverse disciplines to produce new knowledge. This analysis implicitly assumes that each individual introduces ideas from their own research community and that, by pooling knowledge and skill, creativity and innovation is enhanced. The author discipline variable was measured by the authors' self-reported departmental affiliation (e.g. Department of Accounting) at the time the research was published. An author's departmental affiliation may not always accurately reflect the disciplinary background of the author; nor does it mean that multiple perspectives will be brought to the project. Regardless of this limitation, diversity in author backgrounds introduces the potential to bring multiple perspectives, representing the diversity of knowledge in accounting research. This variable was captured by counting the number of disciplines attached to authors in published articles. An article with two authors from the same discipline (e.g. Accounting) is awarded a score of 1, whereas two authors from different disciplines (e.g. Accounting and Management) is awarded a score of 2. For example, in Shafer et al. (2016), all three authors were affiliated with the same type of department, 'Accountancy', and is therefore awarded a score of 1 . By contrast, Pinnuck and Shekhar's (2013) article is contributed to by two 
authors affiliated with two distinct disciplines, Accounting and Finance, and is therefore awarded a score of 2 . Coding was problematic in cases where the departmental affiliation included more than one discipline (e.g. Department of Accounting and Finance). In such cases, the researchers conducted a web-based identity search to identify each author's key underlying discipline.

\section{Findings}

\subsection{Descriptive results}

The framework depicted in Figure 1 highlights the components of cross-disciplinary research, emphasising concept-to-concept and methodological integration (integration dimension) and researcher-to-researcher interaction (interaction dimension). The data presented in Table 1 display the extent of conceptual integration. Panel A of Table 1 displays the number of discrete conceptual lenses used within a single article. Few articles were published (62 or $4.3 \%$ ) without an underlying conceptual lens, yet more than half (51.4\%) rely on a single conceptual framing, suggesting that a large proportion of cross-disciplinary research in accounting is mono-disciplinary (Mean $=1.71, \mathrm{SD}=.950$ ). Having said this, $44.3 \%$ of published articles rely on two or more conceptual lens, displaying evidence of crossdisciplinarity, with economics and sociology being dominant in cross-disciplinary research. ${ }^{7}$

Whilst the data in Panel A displays the extent of integration, measured using the number of conceptual lenses, Panel B of Table 1 displays the frequency with which multiple conceptual lenses from unrelated disciplines were combined and used within a single article. The data in Panel B show that $60 \%$ of published articles rely predominantly on the conceptual lens of accounting as a single discipline (Mean $=1.43, \mathrm{SD}=.591$ ). Alternatively, $35.7 \%$ of published articles develop the research using conceptual lenses emanating from multiple disciplines. This data suggests that around one-third of published articles rely on conceptual lenses from multiple disciplines, implying a degree of conceptual integration. Whilst integration is present, mono-disciplinary research in which research relies in a single conceptual lens remains dominant.

Regarding the extent to which cross-disciplinarity is reflected in integrated research methods, Panel $C$ shows the number of times discrete research methods are used and combined within a single article. The data indicate that the majority of published articles (75.9\%) rely on a single method of data analysis, with relatively few articles (19.9\%) adopting

\footnotetext{
${ }^{7}$ The different combinations of conceptual lenses are too numerous to represent in this analysis. The focus of this study centres on capturing multiplicity in cross-disciplinarity by measuring the number of times concepts are combined. The study is less concerned with profiling disciplinary perspectives or identifiable theories. However, the following list (in alphabetical order) is generated for information purposes, representing the most used disciplinary perspectives and examples of conceptual lenses in the sample of published articles: Accounting (conceptual framework of financial reporting); economics (agency theory, rational choice theory); organization and management (contingency theory, stakeholder theory, institutional theory); psychology (identity theory, cognitive theory, attribution theory ); and sociology (Bourdieu, Foucault, feminist theory, labelling theory).
} 
more than one methodological approach (Mean $=1.23, \mathrm{SD}=.503$ ). Document analysis and the Interview methods of research rank first and second, respectively, for all three journals. 'Critical review of literature' ranks third in articles published in AAAJ and CPA, whilst Experimental research ranks third for AOS. In all, the approach to cross-disciplinary research is homogenous with regard to research method; and whilst cross-disciplinarity is wide in conceptual terms, the research approach to data collection and analysis appears narrow and applied within mono-disciplinary boundaries.

Insert Table 1 about here

Interaction at the level of researcher-to-researcher collaboration (Figure 1) is reflected in the data appearing in Table 2. The data in Panel A reflect the extent of co-authorship, where the two largest groups (59.7\%) were produced by two and three authors (Mean $=2.02, \mathrm{SD}=$ .976). Consistent with prior evidence in accounting, few manuscripts were published with four or more authors. The extent to which cross-disciplinary research and the interaction dimension is reflected in co-authorship, the evidence in Table 2 appears promising, with $65.8 \%$ of articles represented by multiple authors. However, co-authorship is but one form of research collaboration. Cross-disciplinary collaboration is potentially more accurately reflected not with the collaborating efforts of co-authorship but with the collaboration of authors from different disciplines. However, like theoretical integration, the data in Panel B show that the vast majority of author collaborations (89.1\%) emanate from the same academic discipline (Mean $=1.12, \mathrm{SD}=.372$ ). Not unsurprisingly, accountancy is the discipline that dominates published research in the sample journals.

Insert Table 2 about here

Relating the data to the Framework in Figure 1, cross-disciplinary research in accounting gradually moves along the continuum of disciplinarities in relation to the integration dimension, with increasing activity in the number of concepts and the number of times concepts from diverse disciplines are used within a research project. This differs somewhat from the data relating to the interaction dimension. In spite of the presence of researcher-toresearcher interaction with multiple co-authorships, this dimension lacks disciplinary interaction when the vast majority of authors collaborate with scholars from the same discipline. The evidence combined (conceptual lens and co-authorship) suggests the presence of 'integration' with the adoption of multiple conceptual lenses, but few authors venture out of their discipline to work with colleagues in 'other' disciplines. The distinguishing feature of cross-disciplinary team-research is its ability to combine and integrate concepts and methods from two or more fields, but this is not evident in the present data.

\subsection{Evaluating the extent of cross-disciplinary accounting research}

The data is further analysed as follows to statistically examine the extent of crossdisciplinarity, to provide a more robust analysis of where cross-disciplinary accounting 
research is situated within the framework. The Kaiser-Meyer-Olkin test and Bartlett's Test of Sphericity are used to test the adequacy of the data for factor analysis (see Table 3 ). The coefficient of KMO test is $0.501>0.5$, indicating that the correlation between the five variables is moderate and that the sample is adequate for factor analysis (Cheung, 1999; Loas et al., 1996; Dunk, 1993). The approximation $\chi 2$ value (1115.744) of Bartlett's Test of Sphericity is significant $(\mathrm{df}=10, \mathrm{p}<0.01)$, indicating that the matrix is positive, supporting the conditions for Principal Component Analysis.

Insert Table 3 about here

Principal Component Analysis (PCA) is a dimension-reduction tool to reduce a large set of variables to a smaller set, prior to running quantitative data analysis. Eigenvalues greater than 1 for a component indicate that there is more than one variable explaining variations in the component. PCA on the five variables extracted two primary components with initial eigenvalues greater than 1 (see Table 4). The eigenvalue of the first component is $1.741,{ }^{8}$ explaining $34.8 \%$ of the total variance of the five variables. The eigenvalue of the second component is 1.233 , explaining $24.7 \%$ of the total variance. The cumulative variance contribution rate is $59.5 \%$, indicating that the original five variables can be adequately explained by the two principal components. The third component is also identified by the total variance explained (see Table 4), and the eigenvalue of this component is 0.987 (less than 1). Component 3 is therefore insignificant as an independent component compared with components 1 and 2 (with eigen values greater than 1 , see Table 4). ${ }^{9}$ The coefficients for component 1 and 2 are presented in Table 5. Even though $N_{-}$methods lies between the two components, it is slightly more significant in Principal Component 1 (coefficient 0.168 ) than in Principal Component 2 (coefficient 0.165). N_methods was consequently placed in Component 1 , represented alongside the elements underlying the integration dimension.

\section{Insert Table 4 about here}

The rotated Method-Tilt and Kaiser Standardized Methods is conducted to better understand the component score coefficients (see Table 5). The coefficient in Principal Component 1 is considered large and is loaded by $N_{-}$conceptual_lens (0.928), N_cross_conceptual_lens (0.922) and, to a lesser degree, N_methods (0.168). Principal Component 1 is consistent with the elements underlying the 'integration dimension' and consequently used to measure the extent of integration in cross-disciplinary accounting research. In Principal Component 2, the coefficients of N_authors (0.784) and N_author_discipline (0.770) are more significant than other elements, suggesting that Component 2 is represented by researcher-to-researcher collaboration and the interaction of disciplines from which the researchers are domiciled. Component 2 is consistent with the

\footnotetext{
${ }^{8}$ A component with eigenvalue of 1.741 explains as much as 1.741 variables do.

${ }^{9}$ Component 3 mainly captures the feature of $\mathrm{N}$-Method, however, its eigenvalue is less than 1 , so it is not one of our main elements. Therefore, we did not calculate the coefficient score for element 3 in table 5.
} 
elements underlying the interaction dimension and consequently used to measure the extent of interaction in cross-disciplinary research. The results of the PCA provide a degree of validation of the hypothesised definitional framework in which the coefficients underlying the components were consistent with the elements underpinning the integration and interaction dimensions. The validation provides a level of confidence that the framework and its dimensions possess value in assessing cross-disciplinary research in accounting. The loading of the variables upon the principal components suggests that the underpinning dimensions accurately reflect the activities that underlie cross-disciplinary accounting research.

Insert Table 5 about here

The significance of each of the five variables is depicted in the Composition Map displayed in Figure 3. The N_conceptual_lens and N_cross_conceptual_lens play a significant role in the integration component, with support from $\mathrm{N}$-methods. A relatively high number of articles in the sample journals adopt and merge multiple conceptual lenses in their research, while diversification in methodological approaches is less common. Considering the interaction component, both N_authors and N_author_discipline were deemed important, indicating a relatively high number of articles were published by multiple authors albeit the majority of collaborations occurring within the same discipline.

Insert Figure 3 about here

The component score coefficients from Table 5 were subsequently used to construct two composite indexes of cross-disciplinarity. The following component score functions were constructed:

$$
\begin{aligned}
& \text { Integration }=0.013 \times \text { N_authors }-0.013 \times \text { N_author_discipline }+0.168 \times \\
& \text { N_methods }+0.928 \times \text { N_conceptual_lens }+0.922 \times \text { N_cross_conceptual_lens } \\
& \text { Interaction }=0.784 \times \text { N_authors }+0.770 \times \text { N_author_discipline }+0.165 \times \\
& \text { N_methods }-0.002 \times \text { N_conceptual_lens }-0.005 \times N \text { _cross_conceptual_lens }
\end{aligned}
$$

The composite index of cross-disciplinarity was constructed to identify the presence of cross-disciplinary cognition:

$$
\text { Crossdisciplinary }=\sum_{n} \sum_{i=1}^{5} \text { Coefficient }_{n i} \times Q_{-} \text {score }_{n i} \times V C R_{n}
$$




$$
\begin{aligned}
& \sum_{i=1}^{5} \text { Coefficient }_{n i} \times Q_{-} \text {score }_{n i}=\alpha \times N_{-} \text {authors }+\beta \times N_{-} \text {author_discipline } \\
& +\lambda \times N_{-} \text {methods }+\eta \times N_{-} \text {conceptual_lens }+\delta \times N_{-} \text {cross_conceptual_lens }
\end{aligned}
$$

Where $\boldsymbol{Q}_{n i}$ Score represents the original value of variables $i$ ( $N$ _authors, N_author_discipline, N_methods, N_conceptual lens, N_inter_conceptual lens) in the principal component $n$ (component 1 represents the 'integration' dimension, component 2 represents 'interaction' dimension);

Coefficient $_{n i}$ represents the score of variable $i$ in the principal component $n$ (obtained from Table 1 Component Score Coefficient Matrix);

$\boldsymbol{V} \boldsymbol{C} \boldsymbol{R}_{\boldsymbol{n}}$ represents the variance contribution percentage of principal component $\mathrm{n}$ (as described above: component 1 explains $34.792 \%$ of the total variance of five variables; component 2 explains $24.681 \%$ of the total variance of five variables).

The Composite Index of cross-disciplinarity was calculated for all 1,461 articles. Three different degrees of cross-disciplinarity were identified through plotting (see Figure 4). The degree of cross-disciplinarity identified by multi-disciplinary research includes published articles with the smallest composite, measured by low integration and low interaction; the degree of cross-disciplinarity identified by inter-disciplinary research includes articles with a balanced composite index of cross-disciplinarity as measured by a moderate level of integration and a moderate level of interaction; and the degree of cross-disciplinarity identified by trans-disciplinary research includes published manuscripts with a large composite index as measured by a high level of integration and a high level of interaction. The distribution of observations trends toward the $\mathrm{Y}$-axis, demonstrating that more than half of the composite indices comprising publications in accounting cross-disciplinary research is contributed by the 'integration' dimension (34.792\%/59.5\%), while the contribution of the 'interaction' dimension is comparatively low (24.7\%/59.5\%). Moreover, the 'integration' dimension ( $N$ _conceptual_lens and N_cross_conceptual_lens) represents the dominant variables influencing the degree of cross-disciplinarity, whereas the contribution of N_methods to the integration dimension is small. In the 'interaction' dimension, both N_authors and N_author_discipline are significant to this dimension.

Overall, the results of PCA confirm the descriptive analysis, indicating that crossdisciplinary research in accounting is mainly driven by the integration dimension, influenced by conceptual application and integration, and supported in part by the diversity of methodological approaches. Cross-disciplinarity in accounting, when it occurs, is led by a 
moderate degree of conceptual integration with less emphasis on researcher-to-researcher interaction as measured in terms of co-authorship.

\section{Insert Figure 4 about here}

\subsection{Cross-disciplinarity and citations}

The analysis in this section assesses the impact of the dimensional structure of the cross-disciplinary framework (integration and interaction dimensions) on the frequency of citations. This study proposes that the average number of annual citations is positively correlated with the level of cross-disciplinary research. Citation data are collected from Google Scholar at the end of 2019, to measure the number of times each article has been cited since the year of publication. However, as total citation count grows with time, a cumulative score disadvantages newer articles that lack the same temporal opportunity to demonstrate the quality or impact of the research. To overcome this problem, an average annual citation is calculated by dividing the number of times an article is cited by the number of years the article is in publication (up to the end of 2019 and inclusive of the year of publication).

Citation data are analysed using the composite measures (principal component 1 integration; and principal component 2 - interaction) to assess the influence of the principal components on the level of average annual citations. While other factors may impact the level of citations, such as the reputation of the authors, the present analysis is focused on the influence of the integration and interaction dimensions. Nevertheless, in order to increase the robustness of this analysis, other important control variables are incorporated to assess factors having an impact on citations. The following variables are expected to have a positive impact on citations per year. The dummy variable Eminent_scholar is identified based on the authors' publication productivity as measured by an author contribution index. ${ }^{10}$ When an article includes an eminent scholar, Eminent_scholar $=1$, otherwise, Eminent_scholar $=0$. An article with an eminent scholar as (co)author is expected to increase the number of citations through both increased quality and Halo-Effects. Crossunit_scholar is used to control for authors affiliated with more than one university. An author with multiple affiliations is considered an esteem factor linked to the reputation of the author Crossunit_scholar $=1$, otherwise, Crossunit_scholar $=0$. Lead_article is defined as the first $5 \%$ published articles in a research theme ${ }^{11}$ thus Lead_article $=1$, otherwise, Lead_article $=0$. The Impact factor is a measure of the frequency in which the average article in a journal has been cited in a

\footnotetext{
${ }^{10}$ The eminent scholar is identified by calculating author index to each scholar. Each paper is awarded a score of 1 , then this score is proportionally allocated among all authors of the publication. If an author's cumulative index is above 5, we classify them as an eminent scholar.

${ }^{11}$ In order to identify lead articles, we classified all papers in different research themes: social and environmental accounting/disclosure, management accounting, financial reporting and practice, accounting research, accounting history, auditing, accounting professional, and others (including government accounting, accounting academia, taxation, accounting education, and accounting information systems).
} 
particular year. The Impact factor reported as at 2019 for each journal, is included in the analysis to control for the impact of the journal on article citations. Journals with high impact are expected to attract the interest of researchers, in turn, drawing attention to the articles published therein, increasing the citation rate of individual articles. The present study adopts the journal impact factor to control for its effect on the level of citations influenced by the quality or popularity of the journal, more than the quality of the individual article. Gendron and Baker (2005) claim that AOS is dominated by two streams of research, the qualitative stream (interpretative/critical) and the behavioral stream (positivist). Scholars in the qualitative community may consider that their research dynamics, norms and conventions are different from the behavioral (positivist) stream. In order to control for this factor, a dummy variable Behavioral_stream $=1$ is used, otherwise Behavioral_stream $=0$. Funding is another control variable included in our analysis. An article sponsored with financial support, is deemed important research or a hot research topic likely to be of interest to the accounting research community, thereby potentially attracting more citations. Finally, citations are expected to increase with the number of years in publication, thus we control for the article's published period $N$ _year.

The Pearson correlation coefficient between the citation rate per year and crossdisciplinarity is 0.1146 , and is significant at the $1 \%$ level (Table 6 ). The correlation exists in both the interaction dimension (Pearson correlation coefficient is $0.0736, p<0.01$ ) and the integration dimension (Pearson correlation coefficient is $0.0891, p<0.01$ ). Thus, the results show a significant positive correlation between the degree of cross-disciplinarity and the citation rate per year. In addition, there is no significant correlation between the integration dimension and interaction dimension (Pearson correlation coefficient is 0.0174 ), confirming the results of the factor analysis in which the two dimensions of cross-disciplinarity are distinctly separate. In addition, Table 6 shows that Eminent_scholar, Impact_factor, Behavioral_stream and $N$ _year have a significant positive correlation with annual citation rate, but not Crossunit_scholar, Lead article, or Funding. It appears that the major influences on citation rate per year include the reputation of the author, the impact of the journal, the type of research undertaken whether it is behavioral, and number of years in publication.

\section{Insert Table 6 about here}

The data in Table 7 report the relationship between cross-disciplinary research and citation rate per year using OLS regression analysis. The F-value is significant at the $1 \%$ level for each model, hence the results are effective. The data reveal a positive relationship between cross-disciplinary research and average citations from 2005 to 2016 (coef. $=0.344$, $t=4.480, p<0.01$ ), suggesting that a high degree of cross-disciplinarity leads to a high level of citations per year. The results reveal that both the integration dimension (coef. $=0.134, t=$ $4.028, p<0.01$ ) and interaction dimension (coef. $=0.066, t=2.202, p<0.05$ ) contribute to the level of citations per year.

Insert Table 7 about here 
The relationship between cross-disciplinary research and citation rate per year is further analyzed using the subsample during 2012-2016, controlling for the impact of the GFC. Considering the review cycle of the three journals, 2012 is selected as the beginning of the subsample, allowing for a lag of three years after publication to assess the impact on citations. The results remain consistent for the period 2012 to 2016, that there is a positive relationship between cross-disciplinary research and citations per year (coef. $=0.517, t=4.662, p<0.01$ ), and that both the integration dimension (coef. $=0.125, \mathrm{t}=2.684, \mathrm{p}<0.01$ ) and interaction dimension (coef. $=0.219, t=4.464, p<0.01$ ) contributed to the level of citations.

Comparing the two sample periods, the regression coefficient of cross-disciplinarity in the period 2012-2016 (0.517) is larger than in the period 2005-2016 (0.344), due mainly to the improvement brought by the interaction dimension. This is because the regression coefficient of the interaction dimension in the period 2012-2016 (0.219) is larger than in the period 2005-2016 (0.066); while the regression coefficient of the integration dimension in the period 2012-2016 (0.125) is smaller than in the period 2005-2016 (0.134). This finding suggests that the 2008 GFC had a larger influence on the collaboration of authors from different disciplines, more than the integration of theories and method. ${ }^{12}$

In terms of control variables, it can be seen from Table 7 that Impact factor, Eminent_scholar and Funding have a significant $(p<0.01$ or $p<0.05)$ and positive correlation with citations per year in all six models. Crossunit_scholar also has a positive relationship with citations per year but is only significant in the period 2005-2016. Unexpectedly, Lead_article, Behavioral_stream and $N$ _year do not have a significant relationship with the citation rate per year, although the direction of the regression coefficient in each variable is positive and is consistent with our expectation in the period 2005-2016.

The joint results of the above citation analysis suggest that high cross-disciplinarity has a positive impact on citations, while further analysis reveals that both the integration dimension and interaction dimension contributed to the level of citations. In all, it appears that author profile is important in attracting immediate citations, particularly during the period following the GFC, while the content of the research, and presumably the nature of research linked to the integration dimension, have a more profound effect on citations over time.

\section{Discussion}

The strength of cross-disciplinary accounting research is tested by relating the manuscript characteristics with in the dimensions of the framework. The findings reveal that a relatively high number of published articles focuses on integrating conceptual perspectives,

\footnotetext{
${ }^{12}$ Other possible factors that enhance author collaboration include: funding sources promoting interdisciplinarity; the rationalization of scientific researcher contributions; and the demands of complex largescale research projects; all of which stem from the realisation or desire that inter-disciplinarity in research helps understand social complex problems such as the GFC.
} 
but that the level of integration is not equally matched with the level of cross-disciplinary researcher interaction. There are various reasons for the failure of cross-disciplinary research to reach higher levels of cross-disciplinarity, some of which assume epistemological and ontological incompatibilities. Differences in conceptual foundations and methods may indeed be too great, or they may be too costly, for scholars to comprehend and to enable collaboration. Despite certain advantages that collaborating authors can expect to gain from co-authorship (see Lohmann \& Eulerich, 2017; Carayol \& Thi, 2005), there does not appear to be any significant drive for cross-disciplinary collaborative research in accounting. It appears that researchers in accounting are motivated to integrate conceptual lenses more than they are motivated to grasp the intricacies involved in initiating cross-disciplinary research between scholars from unrelated disciplines. The core challenge for cross-disciplinary researchers is to move between the prevailing fields of research and engage more widely with fellow researchers from diverse fields.

The findings of this study suggest that research in accounting infrequently reaches high levels of cross-disciplinarity, being limited by the interaction dimension more than the integration dimension. It could be that cross-disciplinary research begins with high expectations but ends with low outcomes. However, rather than being critical of crossdisciplinary accounting research, it could be that existing levels of integration and interaction are those that could realistically be achieved when the transaction costs associated with crossing disciplinary boundaries are high (van Rijnsoever \& Hessels, 2011). Trans-disciplinarity is the peak of cross-disciplinary research, but it is the most difficult to obtain. Researchers who open their research to alternative ways of thinking will incur considerable costs particularly when the cognitive distance between disciplines is high. Canning et al. (2018) suggest that there is nothing preventing scholars in one discipline from exposing themselves to writings and work produced outside of their discipline. However, the key to transcending disciplinary boundaries is more than enlightening oneself to alternative viewpoints, it requires the expertise of collaborative and multiple authors. The problem for researchers, in explaining why collaboration is avoided, is that collaboration results in fewer synergies than expected when it results in divergences in modes of operating, and issues of free riding, motivation and resourcing (Endenich \& Trapp, 2016; van Rijnsoever \& Hessels, 2011).

If cross-disciplinary research is to become a common reality, scholars need to negotiate new territory at the disciplinary boundaries and to develop research practices specific to the cross-disciplinary project. However, the gatekeeping activities of editors and reviewers is a one barrier to extending the boundaries of knowledge, reinforcing the rigidity of the dominant centre and constraining new trajectories of research (Gendron \& Rodrigue, in press). Michelon (in press) states that innovative research has the potential to be disruptive by shifting the core of the research to the margins. Reinforced by Gendron (2018a), marginalised topics sitting at the boundaries of knowledge is one potential way of achieving cognitive shifts. According to Gendron and Rodrigue (in press), boundary work is fraught with issues when gatekeepers prevent or discourage scholars from working at the fringes of 
disciplinary domains. When gatekeepers are closed to novel topics and approaches to research, this stifles innovation and the imagination of researchers. If scholars are to engage in research at the fringes of knowledge, they must feel that being different is not risky and is welcomed by the community of accounting scholars. Gendron and Rodrigue (in press) subsequently call for editors and reviewers to be receptive to novel research examining fringe topics.

The lack of cross-disciplinary interaction, relative to the level of integration, becomes curious when both dimensions have a positive effect on the level of citations. Furthermore, the interaction dimension has a larger effect on the level of citations in the post-GFC period. The findings of the present study suggest that, while both the integration and interaction dimensions contribute to the level of citations, the impact of cross-disciplinary research, as measured through citations, is greatest when interaction is high. This result can be explained in part by Meyer et al. (2018), who find that citations appearing in top accounting journals is driven by many factors including the visibility or the repute of the cited authors. Whilst aspects of co-authorship, such as the reputation of authors, might also raise the level of citations, the data in the post-GFC period show that the level of citations increases more steeply when researchers from diverse disciplines collaborate. When the extent of crossdisciplinarity is measured using factor analysis, the integration dimension comes to the fore in cross-disciplinary research. When the impact of research is measured, the extent of citations is influenced more by the interaction dimension in the post-GFC period than by the integration dimension; and it appears as well that interaction is critical to influencing the level of citations.

Cross-disciplinarity in accounting is visible and arguably more successful in the integration dimension where multiple concepts are integrated or borrowed from other disciplines. This, in part, reflects the efforts of scholars to engage with concepts and theories outside of the discipline of accounting. However, whether the theory is likely to contribute to knowledge will depend on how well borrowed theories are integrated into accounting research and how well they extend existing knowledge (Dyckman \& Zeff, 1984). Whilst theoretical borrowing in research provides a novel lens by which observable data are interpreted, it does not always lend itself to new theoretical framings. In other words, theories adopted from one field may not always be appropriate or adaptable to the accounting discipline, resulting in perfunctory applications (Dyckman \& Zeff, 1984). In addition, research that borrows or transposes a theoretical framing from another discipline, while consistent with rudimentary definitions of cross-disciplinarity, is fundamentally monodisciplinary. Multiplicity is critical to the notion of cross-disciplinarity: a singular conceptual framing applied outside of the discipline in which the phenomenon is studied is not, in strict terms, cross-disciplinary. Any conscious attempt to define or perform cross-disciplinary research should involve a strategy for integrating disciplinary collaboration. 


\section{Conclusion}

The impetus for this study drew from the limitation of the accounting literature to adequately address the meaning of cross-disciplinary research. A review of this phrase across a variety of disciplines provides two crosscutting dimensions (integration and interaction) to identify, explain and think about cross-disciplinary research. The interaction of these dimensions creates the potential for 'cognitive shifts', considered a major benefit of crossdisciplinary research. The dimensions derived from the definitional framework not only influence how cross-disciplinarity can be conceptualised but also provide the mechanism to evaluate cross-disciplinary research in a systematic manner through the publication outlets of three leading cross-disciplinary accounting research journals. The benefits of the framework presented in this study are thus twofold. First, the framework challenges current definitions of cross-disciplinary research advocated in the accounting literature as representing theoretical integration with little reference to methodological integration or collaboration. The framework builds on the notion of cross-disciplinarity in accounting by emphasising the interaction dimension, to expand knowledge and meaning through the collaboration of scholars with complementary expertise and skills. Second, the framework provides a benchmark upon which to conceptualise research variables and outcomes which, at present, are disconnected. The framework and its dimensions aim to promote a fuller discussion and analysis of cross-disciplinary accounting research by highlighting the building blocks necessary to work towards cognitive shifts and the benefits of cross-disciplinary research.

The findings suggest that cross-disciplinary accounting research reaches a moderate level of integration and a low level of interaction, resembling more closely multi-disciplinary research than trans-disciplinary research. The failure to transcend disciplinary boundaries in a significant way is what separates multi-disciplinarity from inter/-trans-disciplinarity in this study, arising from limited engagement with scholars from unrelated disciplines as participants in the research. However, the key to interaction is not simply the bringing together of researchers from different disciplines but the exchange and transfer of knowledge and skills by linking people, places, and expertise in the execution of research to jointly frame a problem, discuss and agree on a methodological approach. There are many factors inhibiting collaboration among scholars from unrelated disciplines; and removing these partitions to encourage collaborative research is critical to the success and advancement of cross-disciplinary and pioneering research in accounting.

Overall, the evidence presented in this study is consistent with definitions of crossdisciplinary accounting research that centre on conceptual integration; however, crossdisciplinary accounting research is limited when it is measured against a more comprehensive definition composed of multiple components comprising the dimensions of integration and interaction. Whilst the reasons contributing to the results are many, this problem is perhaps more fundamental relating to the meaning of cross-disciplinary research. A particularly 
important issue in this regard concerns the variety of cross-disciplinarities, reflecting the different levels of integration and interaction, which are potentially confused and incorrectly labelled. When the term inter-disciplinary is misunderstood or inadequately explained, there is potential for the term to be interpreted and used in an inflationary way. The term 'interdisciplinary research' is used in the accounting literature as an umbrella term to address all things cross-disciplinary, but it is narrowly interpreted and applied in a multi-disciplinary fashion. The lack of a common understanding in accounting becomes a barrier to high levels of cross-disciplinary research, particularly when scholars in accounting rest their claims on the basis that accounting research is founded on a breadth of disciplines uniformly adopting a cross-disciplinary approach to research (Dyckman \& Zeff, 1984; Whitfield \& Reid, 2004). As Roslender and Dillard (2003, p.326) state: “... all accounting research is at its core interdisciplinary in that it draws its theory and methodology from other disciplines." To the extent that this claim is allocated merit, discussion on cross-disciplinary research ceases at the point at which theories are borrowed from other disciplines.

The results of the analysis undertaken in this study should be interpreted with caution. The categorisation of variables such as conceptual lens and method can be subjective; however, this subjectivity was mitigated by a second member of the research team reviewing and discussing ambiguous data until consensus was reached. The interconnectedness of the integration and interaction dimensions is treated as an empirical question in search of statistical relationships; however, correlations should not be interpreted as causation. In addition, the quantitative approach used in this study is vulnerable to endogeneity, in which additional explanatory variables may be omitted from the analysis. Furthermore, whilst the integration of conceptual perspectives through categorisation and frequency counts is evident in the present data, this does not measure the quality of integration which is likely to vary between manuscripts and, in some cases, be superficial. Similarly, whilst co-authorship implies interaction, it does not necessarily result in the sharing of knowledge or skills. Furthermore, frequency counts overlook issues associated with conceptual or methodological proximity by giving the same weight to each observation, when some approaches are spatially closer compared with others.

The robustness of the framework relies on the acceptance of the underpinning dimensions that, at present, remain conjectural until they are critically evaluated, enhanced and empirically tested with further research. Furthermore, data analysis assumes that the relationship between the two dimensions is linear, when it may be a curved relationship influenced by the quantity of integrations and interactions. The linear relationship is arguably valid to a point, but alters when there are too many disciplinary integrations or collaborations. The data are also restricted by the sample based on three cross-disciplinary accounting research journals, and do not consider articles published in other cross-disciplinary or noncross-disciplinary accounting and non-accounting journals. Whilst research in mainstream accounting research journals is less likely to make significant contributions to alternative 
accounting research (Baker \& Bettner, 1997), the framework constructed in Figure 2 is applicable to all forms (cross-disciplinary and mainstream) of research. It is not unreasonable to assume that journals with an editorial policy of promoting mainstream accounting research publish articles with a degree of cross-disciplinarity. Further research could expand the number and genre of journals and the time period in which the data are collected, or perform trend analysis to grasp a wider understanding of cross-disciplinary research and how it has changed with time.

Finally, the study analyses the data by assuming a coherent body of cross-disciplinary research, whereas in reality, the research that comprises the data is characterised by diverse topics. Mainstream research in financial accounting and auditing is similarly assumed to be based on a narrow set of topics and a limited range of methods. Future research could conduct similar analysis on different streams of research in accounting to understand the extent of cross-disciplinarity within specialised journals or bodies of research. For example, research could explore how the results in the present study hold for cross-disciplinarity in mainstream accounting journals. Alternatively, given that the findings show that crossdisciplinarity results in a higher level of citations, exploring the source of citations (accounting or non-accounting research) will prove useful in comparing it to mono-disciplinary research. Overall, this study calls out to researchers for greater contributions of cross-disciplinary insights, facilitated by disciplinary diverse collaborations and alternative methodologies. The cross-disciplinary community is expected to benefit with knowledge sharing opportunities enhancing the reputation of cross-disciplinary scholars and the impact of the research they publish. Qualitative approaches to research in particular, have the capacity to help scholars understand the meaning and benefits of diversity and multiplicity in accounting research, and evolve the practice of cross disciplinary research through reflective practice. 


\section{Reference list}

Aboelela, S. W., Larson, E., Bakken, S., Carraquillo, O., Formicola, A., Glied, S. A., Hass, J., \& Gebbie, K. M. (2007). Defining inter-disciplinary research: conclusions from a critical review of the literature. Health Services Research, 42(1), 329-346.

Acedo, F. J., Barroso, C., Casanueva, C., \& Galán, J. L. (2006). Co-authorship in management and organizational studies: An empirical and network analysis. Journal of Management Studies, 43(5), 957-983.

Alvesson, M., \& Gabriel, Y. (2013). Beyond Formulaic Research: In Praise of Greater Diversity. Organizational Research and Publications, 12(2), 245-263.

Alvesson, M., \& Sandberg, J. (2013). Has Management Studies Lost its Way? Ideas for more Imaginative and innovative Research. Journal of Management Studies, 50(1), 128-152.

Alvesson, M., \& Kärreman, D. (2007). Constructing mystery: Empirical matters in theory development. Academy of Management Review, 32(4), 1265-1281.

Andrikopoulos, A., \& Kostaris, K. (2017). Taxation collaboration networks in accounting research. Journal of International Accounting, Auditing \& Taxation, 28, 1-9.

Baker, C., \& Bettner, M. (1997). Interpretive and critical research in accounting: a commentary on its absence from mainstream accounting research. Critical Perspectives on Accounting, 8, 293-310.

Baker, C.R. (2014). Commentary on 'Trends in Statistically Based Quarterly Cash-Flow Prediction Models.' Accounting Forum, 38(2), 152-154.

Ballas, A., \& Theoharakis, V. (2003). Exploring diversity in accounting through faculty journal perceptions. Contemporary Accounting Research, 20(4), 619-644.

Broadbent, J., \& Guthrie, J. (2008). Public sector to public services: 20 years of "contextual" accounting research. Accounting, Auditing \& Accountability Journal, 21(2), 129-169.

Canning, M., Gendron, Y., \& O’Dwyer B. (2018). Auditing in a Changing Environment and the Constitution of Cross-Paradigmatic Communication Channels. Auditing: A Journal of Practice \& Theory, 37(2), 165-174.

Carayol, N., \& Thi, T. U. (2005). Why do academic scientists engage in inter-disciplinary research? Research Evaluation, 14(1), 70-79.

Carr, G., Loucks, D. P., \& Blöschl, G. (2018). Gaining insight into inter-disciplinary research and education programmes: A framework for evaluation, Research Policy. 47, 35-48.

Chenhall, R.H., \& Smith, D. (2011), A review of Australian management accounting research: 1980-2009. Accounting \& Finance, 51(1), 173-206.

Cheung, S.O. (1999). Critical factors affecting the use of alternative dispute resolution processes in construction. International Journal of Project Management, 17(3), 189-194. 
Choi, B. C., \& Pak, A. W. (2006). Multidisciplinarity, interdisciplinarity and transdisciplinarity in health research, services, education and policy: 1 . Definitions, objectives, and evidence of effectiveness. Clinical \& Investigative Medicine, 29(6), 351-364.

Creswell, J.W. (2015). A Concise Introduction to Mixed Methods Research. Sage, Thousand Oaks.

Davison, J. (2014). Visual rhetoric and the case of intellectual capital. Accounting, Organizations \& Society, 39(1), 20-37.

de Villiers, C., \& Dumay, J. (2013). Construction of research articles in the leading interdisciplinary accounting journals. Accounting, Auditing \& Accountability Journal, 26(6), 876910.

Dumay, J., \& Guthrie, J. (2019). Reflections on inter-disciplinary critical intellectual capital accounting research. Accounting, Auditing \& Accountability Journal, 32, (8), 2282-2306.

Dunk, A. S. (1993). The effect of budget emphasis and information asymmetry on the relation between budgetary participation and slack. Accounting Review, 68(2), 400-410.

Durocher, S., Bujaki, M., \& Brouard, F. (2016), Attracting Millennials: Legitimacy management and bottom-up socialization processes within accounting firms. Critical Perspectives on Accounting, 39, 1-24.

Dyckman, T.R., \& Zeff, S.A. (1984). Two decades of the Journal of Accounting Research. Journal of Accounting Research, 22(1), 225-297.

Endenich, C., \& Trapp, R. (2016). Cooperation for publication? An analysis of co-authorship patterns in leading accounting journals. European Accounting Review, 25(3), 613-633.

Fleischman, R. K., \& Schuele, K. (2009). Co-Authorship in Accounting History: Advantages and Pitfalls. Accounting, Business \& Financial History, 19(3), 287-303.

Fogarty, T. J. (2014). A dream deferred: inter-disciplinary accounting in the US. Accounting, Auditing \& Accountability Journal, 27(8), 1265-1270.

Gendron, Y. \& Rodrigue, M. (in press). On the centrality of peripheral research and the dangers of tight boundary gatekeeping. Critical Perspectives on Accounting.

Gendron, Y. 2018(a). On the elusive nature of critical (accounting) research. Critical Perspectives on Accounting, 50, 1-12.

Gendron, Y. 2018(b). Beyond conventional boundaries: Corporate governance as inspiration for critical accounting research. Critical Perspectives on Accounting, 55, 1-11.

Gendron, Y., \& Baker, C. R. (2005). On inter-disciplinary movements: The development of a network of support around Foucaultian perspectives in accounting research. European Accounting Review, 14(3), 525-569.

Goddard, A. (2010). Contemporary public sector accounting research-An international comparison of journal papers. British Accounting Review, 42(2), 75-87. 
Golde, C.M., \& Gallagher, A.H. (1999). The Challenges of Conducting Inter-disciplinary research in Traditional Doctoral Programs. Ecosystems, 2(4), 281-285.

Gordon, I. M., \& Boland, L.A. (2015). Anatomy of a journal: A reflection on the evaluation of Contemporary Accounting Research, 1984-2010. Accounting History, 20(4), 464-489.

Guthrie, J. \& Parker, L. (2004). Diversity and AAAJ: inter-disciplinary perspectives on accounting, auditing and accountability. Accounting, Auditing \& Accountability Journal, 17(1), 7-16.

Guthrie, J. \& Parker, L. (2014). The global accounting academic: what counts! Accounting, Auditing \& Accountability Journal, 27(1), 2-14.

Hart, R. (2000). Co-authorship in the Academic Library Literature: A Survey of Attitudes and Behaviors. The Journal of Academic Librarianship, 26(5), 339-345.

Hopwood, A.G. (1983). On trying to study accounting in the contexts in which it operates. Accounting, Organizations \& Society, 8(2-3), 287-305.

Huutoniemi, K., Klein, J. T., Bruun, H., \& Hukkinen, J. (2010). Analysing interdisciplinarity: Typology and indicators. Research Policy, 39(1), 79-88.

Jacobs, K. (2012). Making sense of social practice: theoretical pluralism in public sector accounting research. Financial Accountability \& Management, 28(1), 1-25.

Jeacle, I., \& Carter, C. (2014). Creative spaces in inter-disciplinary accounting research. Accounting, Auditing \& Accountability Journal, 27(8), 1233-1240.

Jones, M. J., \& Roberts, R. (2005). International Publishing Patterns: An Investigation of Leading UK and US Accounting and Finance Journals. Journal of Business Finance \& Accounting, 32(5-6), 1107-1140.

Kenneth, S.L. (2014). Trends in Statistically Based Quarterly Cash-Flow Prediction Models. Accounting Forum, 38(2),145-151.

Klein, J.T. (2008). Evaluation of inter-disciplinary and transdisciplinary research: a literature review. American Journal of Preventive Medicine, 35(2), 116-123.

Lehman, C., Annisette, M., \& Agyemang, G. (2016). Immigration and neoliberalism: three cases and counter accounts, Accounting, Auditing \& Accountability Journal, 29(1), 43-79.

Leimu, R., \& Koricheva, J. (2005). What determines the citation frequency of ecological papers? Trends in Ecology \& Evolution, 20(1), 28-32.

Llewelyn, S. (2003). What counts as "theory" in qualitative management and accounting research? Introducing five levels of theorizing. Accounting, Auditing \& Accountability Journal, 16(4), 662-708.

Loas, G., Otmani, O., Verrier, A., Fremaux, D., \& Marchand, M.P. (1996). Factor Analysis of the French version of the 20-ltem Toronto Alexithymia Scale (TAS-20). Psychopathology, 29(2), 139-144. 
Lohmann, C., \& Eulerich, M. (2017). Publication trends and the network of publishing institutions in accounting: data on The Accounting Review, 1926-2014. Accounting History Review, 27(1), 1-25.

Loo, I. D. \& Lowe, A. (2011). Mixed methods research: don't - "just do it". Qualitative Research in Accounting \& Management, 8(1), 22-38.

Meyer, M., Waldkirch, R.W., Duscher, I., \& Just, A. (2018). Drivers of citations: An analysis of publications in "top" accounting journals. Critical Perspectives on Accounting, 51, 24-46.

Michelon, G. (in press). Accounting research boundaries, multiple centers and academic empathy. Critical Perspectives on Accounting.

Morillo, F., Bordons, M., \& Gómez, I. (2003). Interdisciplinarity in science: A tentative typology of disciplines and research areas. Journal of the American Society for Information Science and Technology, 54(13), 1237-1249.

Moser, D. V. (2012). Is Accounting Research Stagnant? Accounting Horizons, 26(4), 845-850.

Newell \& Galliers (2000). More than a Footnote: The Perils of Multidisciplinary Research Collaboration. AMCIS 2000, 1-6.

O’Dwyer, B. \& Unerman, J. (2014). Realizing the potential of interdisciplinarity in accounting research. Accounting, Auditing \& Accountability Journal, 27(8), 1227-1232.

Oler, D.K., Oler, M. J., \& Skousen, C. J. (2010). Characterizing accounting research. Accounting Horizons, 24(4), 635-670.

Orij, R. (2010). Corporate social disclosures in the context of national cultures and stakeholder theory. Accounting, Auditing \& Accountability Journal, 23(7), 868-889.

Parker, L.D. (2005). Social and environmental accountability research: A view from the commentary box. Accounting, Auditing \& Accountability Journal, 18(6), 842-860.

Pinnuck, M.\& Shekhar, C. (2013). The profit versus loss heuristic and firm financing decisions. Accounting, Organizations \& Society, 38(6-7), 420-439.

Porter, A.L., Roessner, J.D., Cohen, A.S., \& Perreault, M. (2006). Inter-disciplinary research: meaning, metrics and nurture. Research Evaluation, 15(3), 187-195.

Prather, J., \& Rueschhoff, N. (1996). An analysis of international accounting research in US academic accounting journals, 1980 through 1993. Accounting Horizons, 10(1), 1-17.

Qin, J., Lancaster, F.W., \& Allen, B. (1997). Types and levels of collaboration in interdisciplinary research in the sciences. JASIS, 48(10), 893-916.

Rafols, I., \& Meyer, M. (2010). Diversity measures and network centralities as indicators of interdisciplinarity: Case studies in Bionanoscience. Scientometrics, 82, 263-287.

Rafols, I., Leydesdorff, L., O’Hare, A., Nightingale, P., \& Stirling, A. (2012). How journal rankings can suppress inter-disciplinary research: A comparison between innovation studies and business \& management. Research Policy, 41(7), 1262-1282. 
Reinstein, A., \& Calderon, T.G. (2006). Examining accounting departments' rankings of the quality of accounting journals. Critical Perspectives on Accounting, 17(4), 457-490.

Reiter, S. A., \& Williams, P. F. (2002). The structure and progressivity of accounting research: the clrisis in the academy revisited. Accounting, Organizations \& Society, 27, 575-607.

Richardson, A.J. (2015). Quantitative research and the critical accounting project. Critical Perspectives on Accounting, 32, 67-77.

Rosenfield, P.L. (1992). The potential of transdisciplinary research for sustaining and extending linkages between the health and social sciences. Social Science \& Medicine, 35(11), 1343-1357.

Rosenstreich, D., \& Wooliscroft, B. (2009). Measuring the impact of accounting journals using Google Scholar and the g-index. British Accounting Review, 41(4), 227-239.

Roslender, R., \& Dillard, J.F. (2003). Reflections on the inter-disciplinary perspectives on accounting project. Critical Perspectives on Accounting, 14, 325-351.

Rossini, F.A. \& Porter, A.L. (1979). Frameworks for integrating inter-disciplinary research. Research Policy, 8(1), 70-79.

Schummer, J. (2004). Multidisciplinarity, interdisciplinarity, and patterns of research collaboration in nanoscience and nanotechnology. Scientometrics, 59(3), 425-465.

Shafer, W. E., Simmons, R. S., \& Yip, R. W. Y. (2016). Social responsibility, professional commitment and tax fraud. Accounting, Auditing \& Accountability Journal, 29(1), 111-134.

Smith, M. (2019). Research Methods in Accounting. SAGE Publications Limited.

Steele, T.W., \& Stier, J.C. (2000). The impact of inter-disciplinary research in the environmental sciences: a forestry case study. Journal of the American Society for Information Science, 51(5), 476-484.

Stock, P., \& Burton, J.F. (2011). Defining Terms for Integrated (Multi-Inter-TransDisciplinary) Sustainability Research. Sustainability, 3, 1090-1113

Tuck, P. (2010). The emergence of the tax official into a T-Shaped knowledge expert. Critical Perspectives on Accounting, 21, 584-596.

Tucker, B.P., \& Parker, L.D. (2013). Out of control? Strategy in the NFP sector: the implications for management control. Accounting, Auditing \& Accountability Journal, 26(2), 234-266.

Tweedie, D. \& Hazelton, J. (2019). Economic inequality: problems and perspectives for interdisciplinary accounting research. Accounting, Auditing \& Accountability Journal, 32(7), 19822003.

Van Helden, G.J. (2005). Researching public sector transformation: the role of management accounting. Financial Accountability \& Management, 21(1), 99-133.

van Rijnsoever, F.J., \& Hessels, L.K. (2011). Factors associated with disciplinary and interdisciplinary research collaboration. Research Policy, 40(3), 463-472. 
Wagner, C. S., Roessner, J. D., Bobb, K., Klein, J. T., Boyack, K. W., Keyton, J., \& Börner, K. (2011). Approaches to understanding and measuring inter-disciplinary scientific research (IDR): A review of the literature. Journal of Informetrics, 5(1), 14-26.

Whitfield, K., \& Reid, C. (2004). Assumptions, ambiguities, and possibilities in interdisciplinary population health research. Canadian Journal of Public Health/Revue Canadienne de Sante'e Publique, 95(6), 434-436.

Wood, D.A. (2016). Comparing the publication process in accounting, economics, finance, management, marketing, psychology, and the natural sciences. Accounting Horizons, 30(3), 341-361. 